Science 18 April 2014:

Vol. 344 no. 6181 pp. $266-267$

DOI:10.1126/science.1252963

Perspective

\title{
Novelty Trumps Loss in Global Biodiversity
}

John M. Pandolfi, Catherine E. Lovelock | 1 Comments

Although global biodiversity is declining, local ecosystems are not systematically losing diversity, but rather experiencing rapid turnover in species. [Also see Report by Dornelas et al.]

\section{Comments}

\section{Joao Pedro Barreiros}

Invasions Changing Marine Biodiversity. J.M. Pandolfi \& C.E. Lovelock Perspective in Ecology "Novelty Trumps Loss in Global Biodiversity" (18 April, 344, 266) point that “...ecosystems decline around the world is described in terms of biodiversity loss" and emphasize the importance of knowing accurate data regarding $\alpha$ and $\beta$ diversity. In marine ecosystems, this approach if of great importance since a vast number of communities suffer complex (often understudied) community shifts especially under a $\beta$ diversity perspective. The most significant marine species' turnover are the shifts caused by Lessepsian migrants (LM) in the Mediterranean's eastern basin. Recent data presented by (1) show that LM are now numbering 435 records with a negative significant correlation between distances of Mediterranean recipient countries to the Suez Canal clearly indicating a strong implantation of invasive species in the eastern Mediterranean. Another example of threatened marine ecosystems caused by introduction is the Lionfish invasion in the Caribbean as broadly explained by (2). Global marine biodiversity also fits into the comprehensive work by (3) but seem to gain insufficient attention from researchers and lack wider actions that should have been urgently implemented in due time. Although popular empirical feeling might well regard these type of marine invaders as just a different food source (mainly fish) for local communities, an aspect also referred by (2), reality shows that long established communities are being wiped out by invaders and while a diversity does seem to remain constant or even increase at the cost of local species' extinction (4), $\beta$ diversity does need a stronger monitoring effort in marine ecosystems. The dramatic species' turnover in the eastern Mediterranean clearly shows the colossal impact of invasive species that will, almost inevitably, change the vast majority of its marine communities with no hope of recovery (5). This trend is increasing and seems to be irreversible.

References 1. A.L. Nunes et al., Aquat. Inv. 9, (2014);

http://www.aquaticinvasions.net/2014/Supplements/Al 2014 Nunes etal Supp... 2. C. Pala, 
Science 343, 591 (2014). 3. M. Dornelas et al., Science 344, 296 (2014). 4. E.S. Poloczanska et al., Nat. Clim. Change 10.1038/nclimate1958 (2013). 5. S. Katsanevakis et al., Ocean Coast. Manage. 76, 64 (2014); http://dx.doi.org/10.1016/j.ocecoaman.2013.02.024

Submitted on Mon, 05/05/2014 - 15:21

\section{DAAAS HighWirePress}

Science Online Home | News | Science

Journals | Careers | Multimedia | Collections | Help | Site

Map | RSS

Subscribe | Feedback | Privacy Policy | About Us | Advertise With

Us | Contact Us

(C) 2010 American Association for the Advancement of Science. All

Rights Reserved.

AAAS is a partner of HINARI, AGORA, OARE, PatientInform,

CrossRef, and COUNTER. 